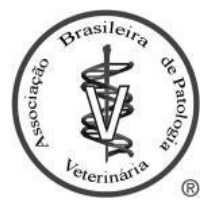

Original Full Paper

\title{
A retrospective study of neoplasms in ornamental and pet birds diagnosed at the Hospital de Aves of the Universidad Nacional Autónoma de México (2007-2014)
}

\author{
Félix Sánchez-Godoy ${ }^{1}$, Irely Ledesma-Ramírez ${ }^{2}$, Elizabeth Morales-Salinas ${ }^{3 *}$ \\ ${ }^{1}$ Departamento de Medicina y Zootecnia de Aves. Facultad de Medicina Veterinaria y Zootecnia, Universidad Nacional Autónoma de México. Av. \\ Universidad 3000, Ciudad Universitaria, 04510, Ciudad de México, México. \\ ${ }^{2}$ Atención Veterinaria Especializada. Calle Mendelssohn 48, Colonia Vallejo, Gustavo A. Madero, 07870, Ciudad de México, México. \\ ${ }^{3}$ Departamento de Patología. Facultad de Medicina Veterinaria y Zootecnia, Universidad Nacional Autónoma de México. Av. Universidad 3000, Ciudad \\ Universitaria, 04510, Ciudad de México, México. \\ *Corresponding author: Departamento de Patología, Facultad de Medicina Veterinaria y Zootecnia, Universidad Nacional Autónoma de México. Av. \\ Universidad 3000, Ciudad Universitaria 04510, Ciudad de México, México. Tel: +52-55-56-22-58-88; Fax: +52-55-56-22-67-95; E-mail: \\ moraless@unam.mx
}

Submitted July, 29 ${ }^{\text {th }}$ 2019, Accepted November, $25^{\text {th }} 2019$

\begin{abstract}
A retrospective study including a total of 44 ornamental and pet birds with neoplasms diagnosed at the Hospital de Aves, Facultad de Medicina Veterinaria y Zootecnia, Universidad Nacional Autónoma de México from January 2007 to April 2014 was conducted. Most of affected birds were Psittaciformes $(\mathrm{n}=26,59 \%)$ including budgerigars (Melopsittacus undulatus) $(\mathrm{n}=12 / 26,46.15 \%)$ and amazon parrots (Amazona spp.) $(\mathrm{n}=7 / 26,26.92 \%)$, and followed by Passeriformes and Anseriformes $(\mathrm{n}=7 / 44,15.90 \%$, each) and Galliformes $(\mathrm{n}=4 / 44,9.09 \%)$. The youngest studied bird was a 6.5 -week-old lovebird (Agapornis sp.) with a papilloma, and the oldest bird was a 37-year-old yellow-naped parrot (Amazona auropalliata) with a hemangiosarcoma. Most of the affected birds were adults $(\mathrm{n}=23,52.27 \%)$. The gender was determined for 17 birds (38.63\%), of which eight (47.05\%) were females and nine (52.94\%) males. There were 45 reported neoplasms, as one salmon-crested cockatoo (Cacatua moluccensis) had two neoplasms. The two most frequent neoplasms were fibrosarcomas $(n=9 / 45,20 \%)$ and hemangiosarcomas $(n=5 / 45,11.11 \%)$. The largest number of neoplasms was found in the integumentary system $(n=18 / 45,40 \%)$, followed by the reproductive system $(n=10 / 45,22.22 \%)$. Of the 16 types of neoplasms, seven $(43.75 \%)$ were malignant, six $(37.5 \%)$ were benign, and three $(18.75 \%)$ were potentially malignant. This study showed similarities with retrospective previously reported studies and contributes to the knowledge of the neoplastic diseases that occur in ornamental and pet birds in Mexico.
\end{abstract}

Key words: avian, pet, neoplasm, pathology, Mexico.

\section{Introduction}

Neoplasms are common in pet birds, especially in the Psittacidae family (7, 13, 14, 25, 27, 36, 42). The high incidence of neoplasms in these birds may be due to assisted inbreeding, their longer lifespan, which increases the exposure time to potential carcinogenic environmental agents, and the consequent risk of genetic errors or mutations $(5,42,54)$. Pet birds with neoplastic diseases are currently more frequently submitted veterinarians before death possibly because the medical care improvements for oncologic patients (44). The following types of neoplasms have been reported in pets birds: epithelial - folliculoma $(3,44)$, basal cell carcinoma $(3,44,58)$, squamous cell carcinoma (12, 31), papilloma $(29,32,38)$, cholangiocarcinoma $(11,15,33)$, pulmonary carcinoma $(20,32)$, air sac carcinoma (30, 40, 42) and renal carcinoma $(32,54)$; mesenchymal - fibroma $(32,41)$ and fibrosarcoma $(7,27,45)$, hemangioma and hemangiosarcoma $(7,44,55)$, lipoma and liposarcoma $(7$, 
27), chondrosarcoma (32), hemangiolipoma (50), osteoma and osteosarcoma $(6,17,51)$, leiomyosarcoma $(2,32)$, and rhabdomyosarcoma (1); hematopoietic and hemolymphatic - lymphoma (7, 8, 32), myelolipoma $(25,35)$ and thymoma $(23,44)$; glandular - adenomas and adenocarcinomas of different systems $(15,32,40,44)$; neuroendocrine - melanoma $(7,32,53)$; ovarian carcinoma and adenocarcinoma $(21,32,44)$ and granulosa cell tumor (49); testicular - seminoma, Sertoli cell tumor, interstitial cell tumor and teratoma $(26,32,44,47,49,57)$; intracranial tumors - ependymoma, choroid plexus tumours, adenoma and adenocarcinoma of the adenohypophysis (22, 56) and neuroblastoma (9). A retrospective study of neoplasms was conducted of birds submitted to the named hospital from January 2007 to April 2014 in order to identify the neoplastic diseases affecting ornamental and pet birds diagnosed at the Hospital de Aves, Facultad de Medicina Veterinaria y Zootecnia, Universidad Nacional Autónoma de México.

\section{Materials and methods}

\section{Data collection and analysis}

The database of the Hospital de Aves, Facultad de Medicina Veterinaria y Zootecnia, Universidad Nacional Autónoma de México (UNAM) during the above mentioned period was analyzed. The identification, number and frequencies of ornamental and pet birds were obtained according to order, family, genus and species of affected bird with final histopathologic diagnosis of neoplastic conditions, cell line involved, gender of birds, affected system, and neoplasm biological behavior. In addition, the age of the studied birds was considered according to the species included in this study, being divided into the following categories: chick (weeks), juvenile (months/years), sexually mature (weeks/months/years), adult (weeks/years) and geriatric (years) as previously described $(10,59)$.

\section{Histopathology}

A complete evaluation of the 44 cases of birds diagnosed with neoplastic conditions was performed histopathologically. The formalin-fixed, paraffinembedded tissue blocks of the named cases were sectioned at 3- $\mu \mathrm{m}$ thick and stained with hematoxylin and eosin (H\&E) by routine procedures. To support the performed histological identification and classification, a selection of tumors was stained with Masson's trichrome (MT), periodic acid-Schiff (PAS), diastase-PAS (PAS-D), Mallory's phosphotungstic acid hematoxylin (PTAH) and Ziehl-Neelsen stains (ZN). The samples were obtained from 21 biopsies and 23 necropsies of the birds.

\section{Immunohistochemistry}

To support the diagnosis of some neoplasms, primary antibodies against desmin (labels smooth and striated muscle cells), actin smooth muscle (labels smooth muscle cells, myofibroblasts and myoepithelial cells), protein S-100 (labels glial, ependymal, and Schwann's cells), cytokeratin (labels keratinized and corneal epidermis, stratified squamous epithelia of internal organs, stratified epithelia, hyperproliferative keratinocytes, and simple epithelia), vimentin (labels intermediate filament protein of the cytoskeleton of vertebrate cells of mesenchymal origin), CD3 (labels $\mathrm{T}$ cells) and CD68 (labels monocytes, macrophages and myeloid cells) were applied (Table 1) (Dako North America, Inc., 6392 Vía Real Carpinteria, California 93013, USA). In all cases, the streptavidin-biotin-peroxidase complex method was used, biotinylated anti-mouse and anti-rabbit secondary antibodies were applied as appropriate, and diaminobenzidine was used as chromogen (Dako North America, Inc.) For the recovery of antigen in all cases, citrate buffer, $\mathrm{pH} 9$, was used in a pressure cooker at $120^{\circ} \mathrm{C}$ for 3 minutes. Staining intensity was interpreted as immunonegative, immunopositive (weak, intermediate, strong) or inconclusive according to the reaction location (nucleus or cytoplasm) (Table 1).

Table 1. Immunohistochemical reagents and protocols used in selected neoplasms diagnosed at the Hospital de Aves of the Universidad Nacional Autónoma de México.

\begin{tabular}{|c|c|c|c|c|c|}
\hline Antibody & Origin & Reactivity & Dilution & Clone & Reaction location \\
\hline Smooth muscle actin* & mouse & $\begin{array}{c}\text { Muscle } \\
\text { (Smooth muscle) }\end{array}$ & $1: 400$ & $1 \mathrm{~A} 4$ & Cytoplasm \\
\hline Desmin* & mouse & Muscle & $1: 100$ & D33 & Cytoplasm \\
\hline S-100 protein* & rabbit & Neural crest cells & $1: 200$ & Polyclonal & Nucleus and cytoplasm \\
\hline Cytokeratin* & mouse & Epithelium & $1: 50$ & AE1/AE3 & Cytoplasm \\
\hline \multicolumn{6}{|l|}{ Subfamily A and B } \\
\hline CD68* & mouse & Macrophages & $1: 1600$ & KP1 & Cytoplasm \\
\hline Vimentin* & mouse & Mesenchymal & $1: 50$ & V9 & Cytoplasm \\
\hline CD3* & rabbit & T lymphocytes & $1: 250$ & Polyclonal & $\begin{array}{l}\text { Membrane and } \\
\text { cytoplasm }\end{array}$ \\
\hline
\end{tabular}

*Dako North America, Inc., 6392 Vía Real Carpinteria, California 93013, USA. 


\section{Results}

Frequencies of birds with a neoplastic process according to their taxonomic classification, age, and gender

The total number of birds submitted to the Hospital de Aves, Facultad de Medicina Veterinaria y Zootecnia, UNAM during the studied period was 7,733, of which $139(1.79 \%)$ were ornamental and pet birds with presumptive clinical diagnoses of neoplastic conditions; of these birds, $44(31.6 \%)$ had definitive histopathologic diagnoses of neoplastic conditions. Of these 44 birds, in descending order, $26(59.09 \%)$ were Psittaciformes, 7 (15.90\%) Passeriformes, 7 (15.90\%) Anseriformes, and 4 (9.09\%) Galliformes (Tables 2 and 3). Of these birds, in descending order, $24(54.54 \%)$ belonged to the family Psittacidae, 7 (15.90\%) Anatidae, 5 (11.36\%) Fringillidae, 4 (9.09\%) Phasianidae, 2 (4.54\%) Cacatuidae, 1 (2.27\%) Turdidae, and 1 (2.27\%) Estrildidae. Regarding age range, the youngest bird was a 6.5-week-old lovebird (Agapornis sp.) with a papilloma, and the oldest bird was a 37-year-old yellow-naped parrot (Amazona auropalliata) with a hemangiosarcoma. According to the age, 23 birds $(52.27 \%)$ were adults, $3(6.81 \%)$ juveniles, 1 (2.27\%) sexually mature, $1(2.27 \%)$ geriatric, and $1(2.27 \%)$ chick (Table 2). For the remaining 15 birds (34.09\%), no possible classification by age was made due to the lack of information (Table 3). Of the 44 birds, gender was determined for only $17(38.63 \%)$, of which $8(47.05 \%)$ were females and $9(52.94 \%)$ males (Tables 2 and 3 ).

Frequency of neoplasms according to cell line, location and biological behavior

In the histological study, a total of 45 neoplasms were reported and included sixteen types of neoplasms which were identified according to cell line origin, of which, in descending order, 9 (20\%) were compatible with soft tissue sarcomas (according to the histochemical and immunohistochemical results described further, they suggest being fibrosarcomas) (Fig. 1), 5 (11.11\%) hemangiosarcomas, $5(11.11 \%)$ carcinomas, $4(8.88 \%)$ granular cell tumors, 3 (6.66\%) adenocarcinomas (Fig. 2), $3(6.66 \%)$ lymphomas, 3 (6.66\%) seminomas, 3 (6.66\%) teratomas, 2 (4.44\%) lipomas (Fig. 3 and 4), 2 (4.44\%) osteosarcomas (Fig. 5), and one case each (2.22\%) of adenoma, osteoma, papilloma, mixed thymoma, granulosa cell tumor and leukemia (Tables 2 and 3).

The location of the 45 neoplasms in the 44 studied birds was as follows. A total of 18/45 (40\%) were located in the integumentary system, of which $5(27.77 \%)$ were fibrosarcomas, 4 (22.22\%) hemangiosarcomas, 4 (22.22\%) granular cell tumors, $2(11.11 \%)$ lipomas, $2(11.11 \%)$ basal cell carcinomas, and $1(5.55 \%)$ papilloma. A total of 10/45 $(22.22 \%)$ neoplasms affected the reproductive system, of which $3(30 \%)$ were seminomas, $3(30 \%)$ testicular teratomas, 2 (20\%) ovarian carcinomas, 1 (10\%) granulosa cell tumor, and $1(10 \%)$ ovarian adenocarcinoma. A total of $7 / 45(15.55 \%)$ neoplasms affected the musculoskeletal system, of which $3(42.85 \%)$ were fibrosarcoma, 2 (28.57\%) osteosarcoma, 1 (14.28\%) osteoma, and 1 (14.28\%) hemangiosarcoma. A total of 5/45 (11.11\%) neoplasms affected the hemolymphatic system, of which 3 $(60 \%)$ were multicentric lymphomas, 1 (20\%) mixed thymoma, and 1 (20\%) leukemia. A total of 4/45 (8.88\%) neoplasms affected the digestive system, of which $1(25 \%)$ was hepatic adenoma, $1(25 \%)$ adenocarcinoma of the cloaca, 1 (25\%) fibrosarcoma of the beak, and $1(25 \%)$ squamous cell carcinoma of the tongue. Only 1 (1/45, $2.22 \%$ ) neoplasm, a pulmonary adenocarcinoma, was located in the respiratory system.

According to the biological behavior, of the 16 types of neoplasms, 7 (43.75\%) were malignant including fibrosarcoma, hemangiosarcoma, carcinoma, adenocarcinoma, lymphoma, osteosarcoma and leukemia, $6(37.5 \%)$ benign including granular cell tumors, lipoma, adenoma, osteoma, papilloma and mixed thymoma, and 3 $(18.75 \%)$ potentially malignant including seminoma, teratomas and granulosa cell tumor (Tables 2 and 3).

\section{Special stains and immunohistochemistry}

Only 6 of the 9 neoplasms diagnosed as compatible with soft tissue sarcomas were stained with MT, which showed positivity for collagen (Fig. 1). The immunohistochemical results of 7 of 9 of these neoplasms showed variable immunopositivity for vimentin (4 weak, 3 intermediate and none strong) (Fig. 6), were immunonegative for cytokeratin and S-100 protein, and inconclusive for smooth muscle actin and desmin.

For the thymoma, the immunohistochemical results showed intermediate immunopositivity in lymphoid neoplastic cells for CD3, and the Hassall's corpuscles showed strong immunopositivity for cytokeratin.

The 4 granular cell tumors showed PAS positive intracytoplasmatic granules, resistant to digestion with PAS-D (which ruled out the presence of glycogen), and negative results for PTAH (no striations were observed) and $\mathrm{ZN}$. The immunohistochemical results for one of these tumors showed intermediate immunopositivity for smooth muscle actin and desmin and was immunonegative for CD68, cytoqueratin and protein S-100.

\section{Discussion}

Of the 44 ornamental and pet birds with neoplastic conditions that were diagnosed during the study period, the largest number of cases belonged to the order Psittaciformes $(\mathrm{n}=26,59.09 \%)$ including budgerigars (Melopsittacus undulatus) $(\mathrm{n}=12 / 26,46.15 \%)$, amazon parrots [(Amazona spp.) $(\mathrm{n}=7 / 26,26.92 \%)$; red-lored parrot (Amazona autumnalis) $(\mathrm{n}=3,42.85 \%)$, white-fronted amazon (Amazona albifrons) $(\mathrm{n}=2,28.57 \%)$, lilac-crowned amazon (Amazona finschi) $(\mathrm{n}=1,14.28 \%)$ and yellow- 
naped amazon (Amazona auropalliata) ( $\mathrm{n}=1,14.28 \%)]$, lovebird (Agapornis sp.) (n=3/26, 11.53\%), monk parakeet (Myiopsitta monachus) ( $\mathrm{n}=1 / 26,3.84 \%)$, salmon-crested cockatoo (Cacatua moluccensis) ( $\mathrm{n}=1 / 26,3.84 \%)$, cockatiel (Nymphicus hollandicus) $(\mathrm{n}=1 / 26,3.84 \%)$ and scarlet macaw (Ara macao) $(\mathrm{n}=1 / 26,3.84 \%)$.

Table 2. Neoplasms, categorized by physiological stage, in 29 ornamental and pet birds diagnosed at the Hospital de Aves, Facultad de Medicina Veterinaria y Zootecnia, Universidad Nacional Autónoma de México from January 2007 to April 2014.

\begin{tabular}{|c|c|c|c|c|}
\hline Taxonomy & Physiological stage/age & Neoplasm & Gender & Biological behavior \\
\hline Psittaciformes & Chick & & & \\
\hline Lovebird & 6.5-week-old & Papilloma & NR & Benign \\
\hline Psittaciformes & Juvenile & & & \\
\hline Budgerigar & 10-month-old & Fibrosarcoma & NR & Malignant \\
\hline White-fronted amazon & 2-year-old & Granular cell tumor & NR & Benign \\
\hline Monk parakeet & 2-year-old & Basal cell carcinoma & NR & Malignant \\
\hline Psittaciformes & Mature & & & \\
\hline Salmon-crested cockatoo & 10-year-old & Fibrosarcoma and Lipoma & $\mathrm{F}$ & Malignant, Benign \\
\hline Psittaciformes & Ádult & & & \\
\hline Cockatiel & 10-year-old & Seminoma & M & Potentially malignant \\
\hline Budgerigar & 1.5-year-old & Fibrosarcoma & NR & Malignant \\
\hline Budgerigar & Adult & Fibrosarcoma & NR & Malignant \\
\hline Budgerigar & 2-year-old & Fibrosarcoma & NR & Malignant \\
\hline Budgerigar & 4-year-old & Seminoma & M & Potentially malignant \\
\hline Budgerigar & 1 year & $\begin{array}{l}\text { Squamous cell carcinoma } \\
\text { of the tongue }\end{array}$ & NR & Malignant \\
\hline Budgerigar & Adult & Granular cell tumor & M & Benign \\
\hline Budgerigar & 3-year-old & Hemangiosarcoma & NR & Malignant \\
\hline White-fronted amazon & 16-year-old & Ovarian carcinoma & $\mathrm{F}$ & Malignant \\
\hline Red-lored Parrot & 20-year-old & Leukemia & NR & Malignant \\
\hline Red-lored Parrot & 23-year-old & Lymphoma & NR & Malignant \\
\hline Lilac-crowned parrot & 28-year-old & Lung adenocarcinoma & NR & Malignant \\
\hline Scarlet macaw & 10-year-old & Lipoma & NR & Benign \\
\hline \multicolumn{5}{|l|}{ Passeriformes } \\
\hline Zebra finch & Adult & Basal cell carcinoma & M & Malignant \\
\hline Canary & 5-year-old & Fibrosarcoma & NR & Malignant \\
\hline Canary & 6-year-old & Lymphoma & NR & Malignant \\
\hline Canary & 7-year-old & Lymphoma & $\mathrm{F}$ & Malignant \\
\hline Canary & 2-year-old & Osteoma & NR & Benign \\
\hline \multicolumn{5}{|l|}{ Galliformes } \\
\hline Common pheasant & Adult & Hemangiosarcoma & $\mathrm{F}$ & Malignant \\
\hline Chicken & 4-year-old & Ovarian adenocarcinoma & $\mathrm{F}$ & Malignant \\
\hline Chicken & 1.6-year-old & Teratoma & M & Potentially malignant \\
\hline \multicolumn{5}{|l|}{ Anseriformes } \\
\hline Mallard & 9-year-old & $\begin{array}{l}\text { Adenocarcinoma of the } \\
\text { cloaca }\end{array}$ & NR & Malignant \\
\hline Mallard & Adult & Seminoma & M & Potentially malignant \\
\hline Psittaciformes & Geriatric & & & \\
\hline Yellow-naped Amazon & 37-year-old & Hemangiosarcoma & $\mathrm{M}$ & Malignant \\
\hline
\end{tabular}

$\mathrm{F}=$ female, $\mathrm{M}=$ male, $\mathrm{NR}=$ not referred. 
Table 3. Neoplasms in 15 ornamental and pet birds with no referred physiological stage diagnosed at the Hospital de Aves, Facultad de Medicina Veterinaria y Zootecnia, Universidad Nacional Autónoma de México from January 2007 to April 2014.

\begin{tabular}{|c|c|c|c|}
\hline Taxonomy & Neoplasm & Gender & Biological behavior \\
\hline \multicolumn{4}{|l|}{ Psittaciformes } \\
\hline Budgerigar & Hepatic adenoma & NR & Benign \\
\hline Lovebird (2) & Fibrosarcoma & NR & Malignant \\
\hline Budgerigar & Hemangiosarcoma & NR & Malignant \\
\hline Budgerigar & Osteosarcoma & NR & Malignant \\
\hline Budgerigar & Granular cell tumor & NR & Benign \\
\hline Red-lored Parrot & Granular cell tumor & NR & Benign \\
\hline \multicolumn{4}{|l|}{ Passeriformes } \\
\hline Canary & Fibrosarcoma & NR & Malignant \\
\hline American robin & Thymoma & $\mathrm{F}$ & Benign \\
\hline \multicolumn{4}{|l|}{ Galliformes } \\
\hline Chicken & Teratoma & M & Potentially malignant \\
\hline \multicolumn{4}{|l|}{ Anseriformes } \\
\hline Mallard & Ovarian carcinoma & $\mathrm{F}$ & Malignant \\
\hline Mallard & Hemangiosarcoma & NR & Malignant \\
\hline Mallard & Osteosarcoma & NR & Malignant \\
\hline Mallard & Granulosa cell tumor & $\mathrm{F}$ & Potentially malignant \\
\hline Muscovy duck & Teratoma & M & Potentially malignant \\
\hline
\end{tabular}

$\mathrm{F}=$ female, $\mathrm{M}=$ male, $\mathrm{NR}=$ not referred.

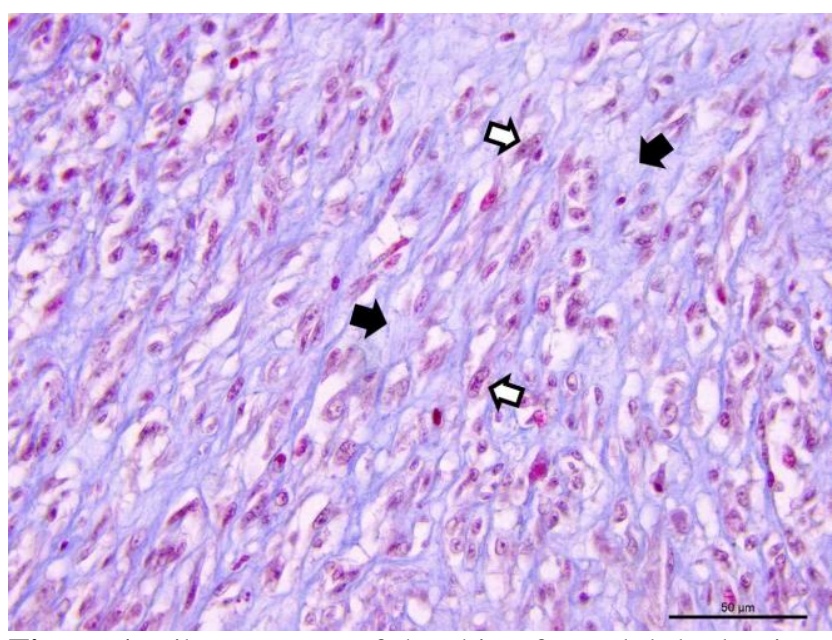

Figure 1. Fibrosarcoma of the skin of an adult budgerigar. Bundles of neoplastic fusiform cells with pleomorphic nuclei, prominent nucleoli (white arrows) and scanty cytoplasm which has indistinct borders and diffuse distribution of blue colored collagen (black arrows) are observed. Masson's trichrome staining. Bar $=50 \mu \mathrm{m}$.

In addition to the possible predisposition to the development of neoplasms in Psittaciformes, this finding reflects the popularity and preference for budgerigars and amazon parrots as pets in households mainly in and around Mexico City. This preference is probably due to their small size (budgerigars), the colors and brilliance of their plumage, and ease of reproduction in captivity, which contributes to inbreeding. Amazon parrots have been highly prized for their ability to imitate and repeat sounds emitted by their owners. In addition, in Mexico, there are numerous free-living amazon parrots, which facilitate their illegal capture and sale. In other studies, the incidence of neoplasms in budgerigars is also reported to be high compared to that in other genera and species, similar to that found in the present study $(13,14,32)$. However, the lower frequency of neoplasms in other birds, such as Passeriformes and Anseriformes ( $\mathrm{n}=7 / 44,15.90 \%$, each) and Galliformes $(n=4 / 44,9.09 \%)$, found in this study does not necessarily indicate that they have a lower predisposition to the development of neoplasms but possibly indicate a lower demand for these birds as pets in Mexico.

Phenotypic characteristics are not always present to easily determine age in birds, and this could be a factor in why the physiological stage for $15(34.09 \%)$ birds in the present study could not be determined. In this regard, it is known that the average lifespan of birds depends on the genus and species and can vary from 6 to 60 or more years (18). Most of the birds of our study were in the adult stage $(n=23 / 29,79.31 \%)$, similarly to a previously published study in which 17 of 23 adult parrots (73.9\%), ranging from 1-to-5-year-old, were included (36). In this regard, adult birds in captivity, unlike free-living birds are recognized to be exposed for longer time periods to unfavorable nutritional factors, such as high fat consumption, prolonged mycotoxin consumption, and potential environmental carcinogens such as aromatic amines and polycyclic aromatic hydrocarbons (5, 13, 16, 54). Mycotoxicosis frequently affects psittacids because diets are composed mainly of grains and seeds, whose prolonged consumption has been associated with hepatic neoplasms (16). 


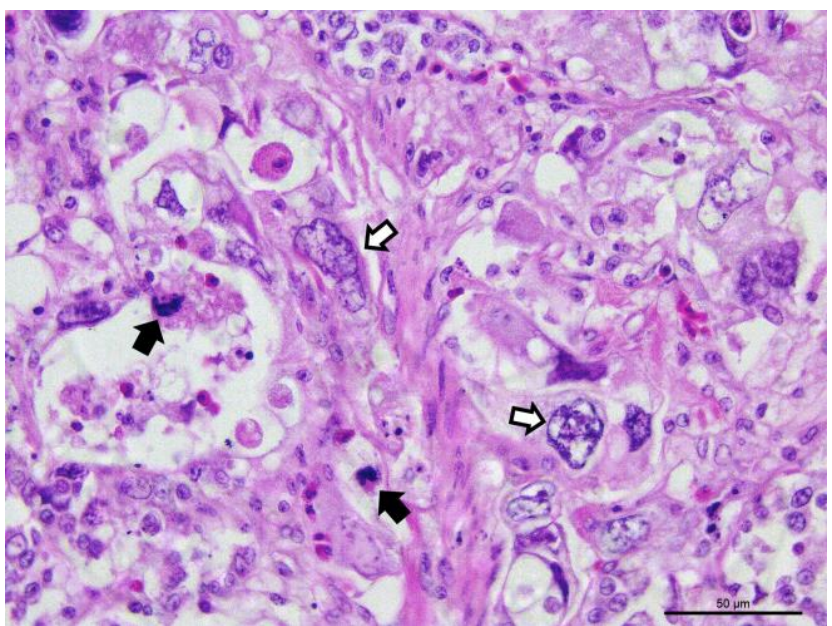

Figure 2. Adenocarcinoma of the cloaca of a 9-year-old mallard. Marked anaplasia of epithelial cells that replace the mucosa of the organ is observed. The cells are pleomorphic, with marked anisokariosis (white arrows) are observed. A variable amount of cytoplasm which has indistinct borders is observed. In addition some atypical mitosis (black arrows) are observed. H\&E staining. Bar $=$ $50 \mu \mathrm{m}$.

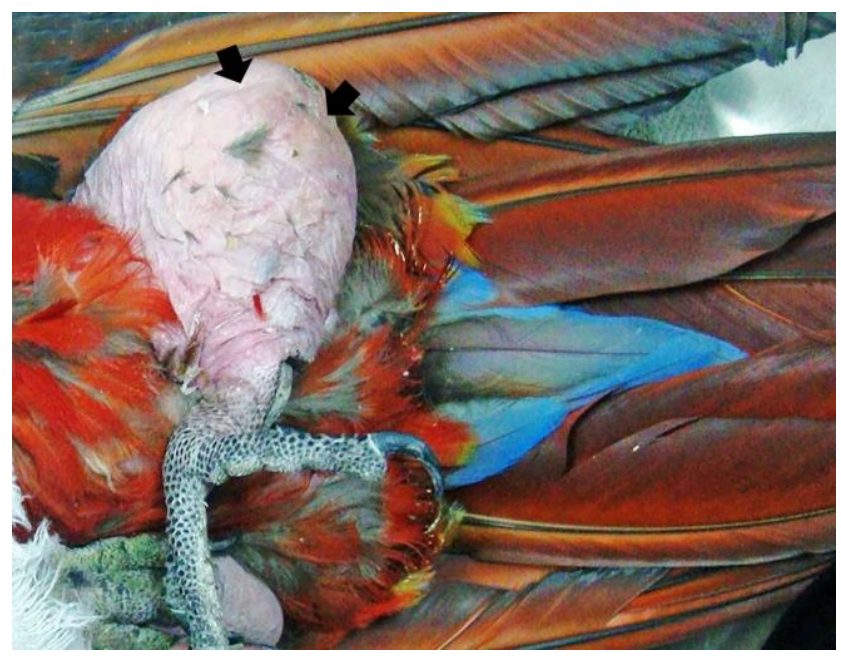

Figure 3. Gross image of the left pelvic limb of a 10-yearold scarlet nacaw, shows a large subcutaneous, palpable, soft, oval-shaped not well delimited neoplasm corresponding to a lipoma (black arrows).

Of the $17(38.63 \%)$ birds in which gender was determined, $8(47.05 \%)$ were females and $9(52.94 \%)$ males, not representing significant differences in gender predisposition to neoplasms. Although some birds of this study present sexual dimorphism, sex could not be determined in $27(61.36 \%)$ of them. The absence of sexual dimorphism in juvenile and adult stages of many bird species showed difficulties to determine sex based on phenotype.

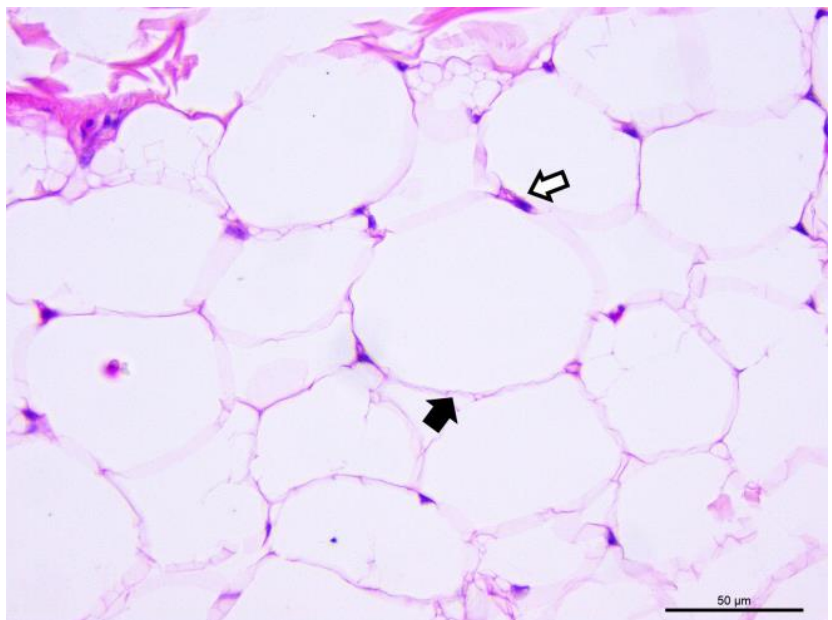

Figure 4. Lipoma of a 10-year-old scarlet macaw. Welldifferentiated mature adipocytes with a large vacuole in the cytoplasm (black arrow) and eccentric and small nuclei (white arrow) are observed. H\&E staining. Bar $=50 \mu \mathrm{m}$.

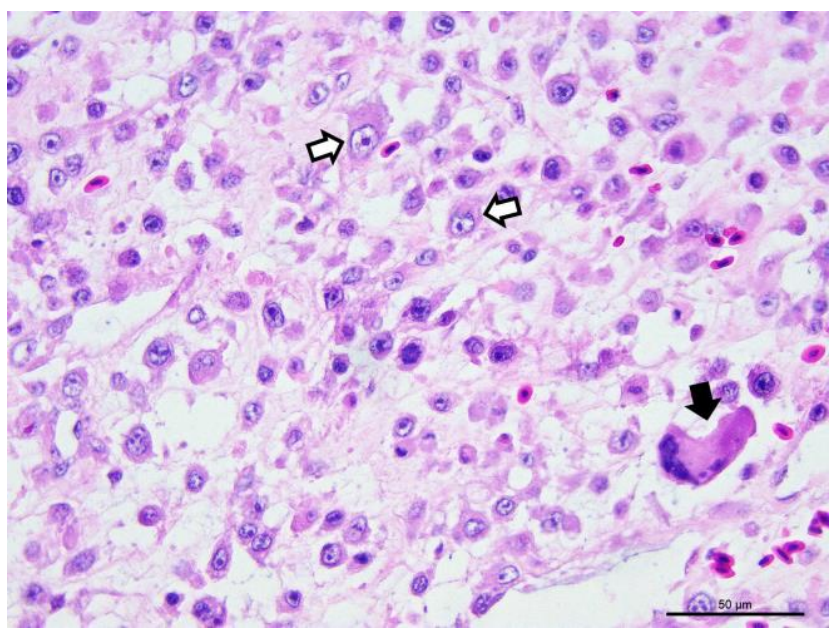

Figure 5. Osteosarcoma in a budgerigar. Pleomorphic osteocytes with large euchromatic nuclei and prominent nucleoli (white arrows) are observed. In the lower rigth corner, a multinucleated cell corresponding to an osteoclast (black arrow) is observed. A small amount of light eosinophilic estracellular matrix possibly consistent with osteoid are observed. H\&E staining. Bar $=50 \mu \mathrm{m}$.

In the present study, neoplasms were most commonly located in the integumentary system $(n=18 / 45$, $40 \%$ ), similarly to other previous studies reporting the skin as the most frequent target of neoplastic conditions in pet birds $(7,24,25)$. In the present study, the most frequent neoplasms in this location were fibrosarcoma $(n=5 / 18$, $27.77 \%)$ and hemangiosarcoma $(n=4 / 18,22.22 \%)$. Some studies mentioned fibrosarcoma and lipoma as the skin neoplasms most commonly found in pet birds $(7,24,27)$. In the present study, only $2(11.11 \%)$ lipomas were identified affecting skin, both 10-year-old salmon-crested cockatoo and scarlet macaw. Lipoma, which were widely 
described in budgerigars, cockatiels, yellow-crowned amazon (Amazona ochrocephala) and rose-breasted cockatoo (Eolophus roseicapillus) $(14,24,44)$, are benign neoplasms that are clinically identified and can be treated avoiding high-energy diets, exercise routines or by surgical resection $(24,48)$. Based on our experience at the Hospital de Aves, Facultad de Medicina Veterinaria y Zootecnia, UNAM, the first above mentioned 2 options are suggested before surgical recession; this may be the reason of the low incidence of lipomas found in our study at our hospital. In addition to the skin fibrosarcomas, 3 other fibrosarcomas were identified in the musculoskeletal system and another in the beak, being the most frequent neoplasm in our study $(n=9 / 45,20 \%)$. This result is similar to previously reported findings in a study were 23 parrots with neoplastic conditions were included and showing the highest incidence of fibrosarcoma (17.3\%) (36). These neoplasms generally involve skin and subcutaneous tissue; the anatomical sites frequently affected are the pelvic limbs and wings, are locally invasive, and rarely metastasize (44). The higher frequency of fibrosarcoma in the present study was directly related to higher number of budgerigars $(\mathrm{n}=12 / 44,27.27 \%)$ submitted to our hospital, and of these, $4(33.33 \%)$ presented with this neoplasm. In this regard, budgerigars have been reported as one of the bird species with the highest frequency of neoplasms and that fibrosarcoma can constitute from $3 \%$ to $14 \%$ of neoplastic conditions in these birds $(13,24)$. In our study, the histochemical stains and the use of the immunohistochemistry, supported the diagnosis of at least 6 of the 9 soft tissue sarcomas. In this regard, although fibrosarcoma and leiomyosarcoma are immunopositive for vimentin, in 6 soft tissue sarcomas which were stained with MT, collagen fibers were detected stained blue, unlike muscle cells whose cytoplasm stains red. On the other hand, the fibrosarcomas are immunonegative for S-100 protein as in 7 of these neoplasms, unlike peripheral nerve neoplasms which are immunopositive for this protein. The combination of the immunohistochemistry results and the detection of collagen fibers in association with the histological characteristics of the neoplasms, suggested that they were fibrosarcomas.

After fibrosarcoma, hemangiosarcoma were the second most frequently diagnosed neoplasms in our study $(\mathrm{n}=5 / 45,11.11 \%)$; in addition to the 4 hemangiosarcoma located in the skin, 1 hemangiosarcoma was located in the locomotor system. These neoplasms were diagnosed in 2 budgerigars, 1 yellow-naped amazon, 1 common pheasant (Phasianus colchicus) and 1 common mallard (Anas platyrhynchos). Cockatiels have been recognized as the pet bird most affected by hemangiosarcoma (44). Other psittacine birds such as budgerigars and yellow-naped amazons were reported to be commonly affected by this neoplasm also, similarly to the findings of the present study $(44,55)$. Cutaneous hemangiosarcoma has been located more frequently in the wings, pelvic limbs and cloaca and have been detected in waterfowl at skin sites with few feathers, suggesting an association with exposure to sunlight, which could have happened in birds with cutaneous hemangiosarcoma in our study (43).

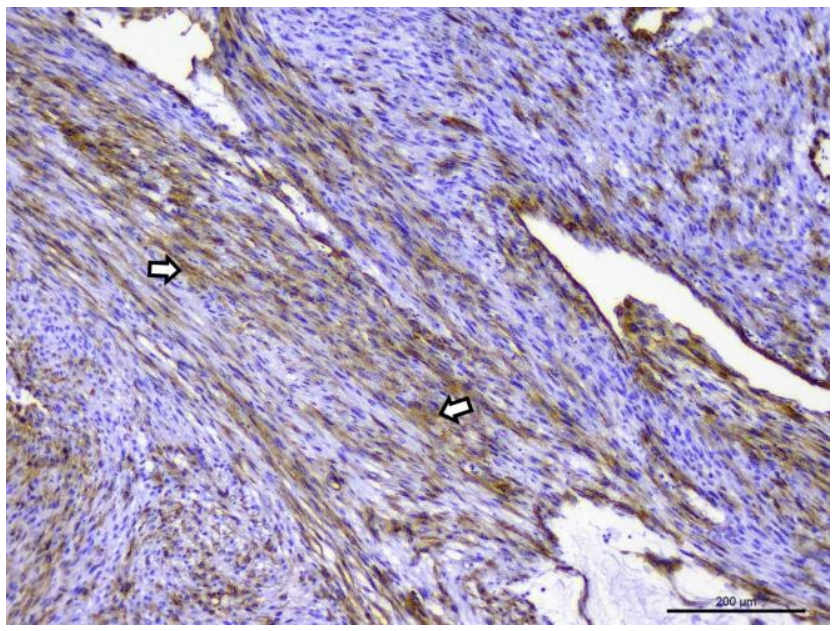

Figure 6. Fibrosarcoma in a lovebird with a fusocellular pattern. Cytoplasmatic immunostaining of intermediate intensity for vimentin (white arrows) is observed. Immunohistochemistry. Bar $=200 \mu \mathrm{m}$.

The identification of granular cell tumors $(n=4 / 18$, $22.22 \%$ ) affecting the integument of 2 budgerigars, 1 redlored parrot and 1 white-fronted amazon in our study is highlighted. The histological characteristics and the results of the histochemical stains were very similar to those previously described for this tumor $(37,39)$. The immunohistochemical results in a granular cell tumor in an adult male budgerigar, suggested myogenic or myofibroblastic origin since it showed intermediate immunopositivity for smooth muscle actin and desmin and was immunonegative for CD68, cytoqueratin and protein S-100. These results are similar to those found in another granular cell tumor diagnosed in a cockatiel (37), which was immunopositive for desmin, muscle common actin and actin, but immunonegative for vimentin and protein S100. Further, in another granular cell tumor diagnosed in a Puerto Rican amazon parrot (39), the tumor, in addition to being immunopositive for desminn, was also immunopositive for vimentin suggesting mesenchymal origin in birds. However, the cellular origin of this neoplasm remains controversial since in other immunohistichemical studies performed in these tumors in humans (46) and horses (4), were immunopositives for protein S-100, which suggests that arise from Schwann cells. The majority of granular cell tumors are bening, although some display malignant behavior $(4,44)$.

Of the 18 neoplasms in the integument, 2 basal cell carcinomas $(11.11 \%)$ were identified, 1 in a monk parakeet and one in a zebra finch (Poephila guttata), as well as a papilloma in a lovebird $(5.55 \%)$. Basal cell carcinoma is a very uncommon epithelial tumor in pet birds; one case has been reported in an Indian runner duck (3) and another in a blue-fronted amazon parrot 
(Amazona aestiva) (58). This neoplasm grows from pluripotent basal cells of the epidermis, and its degree of malignancy is variable (44). In our study, we found 1 papilloma in the skin of a lovebird. Skin papillomas are a benign neoplasms induced by a papillomavirus type 1 and has been reported occasionally in European finches (Carduelis carduelis), canaries (Serinus canaria), chaffinches (Fringilla coelebs), bramblings (Fringilla montifringilla), yellow-necked francolin (Pternistis leucoscepus) and African grey parrot (Psittacus erithacus) affecting the eyelids, junction between the beak and face, cloacal mucosa, legs and toes $(24,29,38,50)$. A herpesvirus also has been suggested to be involved in the etiology of internal papillomatosis of parrots (19).

The reproductive system was the second most frequent location of neoplasms in our study $(n=10 / 45$, $22.22 \%)$. In males, seminomas were found $(n=3 / 10,30 \%)$ in cockatiel, budgerigar and mallard, and testicular teratomas $(n=3 / 10,30 \%)$ were found in chickens (Gallus gallus) $(\mathrm{n}=2)$ and Muscovy duck (Cairina moschata) $(\mathrm{n}=1)$. In our study, testicular teratomas were composed of the 3 germ layers (endoderm, mesoderm and ectoderm) and they did not invade other organs. Testicular neoplasms are uncommon in birds, and, apparently, the highest incidence occurs in budgerigars and cockatiels $(44,49)$. Seminomas usually affect a single testis, they are usually locally invasive masses, showing potential malignant behavior (47). Ovarian neoplasms have been reported more frequently in psittacids, mainly affecting cockatiels and budgerigars (44); In this regard in our study in addition to the ovarian carcinoma identified in 1 white-fronted amazon (psittated) (10\%), 3 additional ovarian neoplasms were identified in other genera: an adenocarcinoma in a chicken $(10 \%)$, a granulosa cell tumor in a mallard $(10 \%)$, and another ovarian carcinoma in a mallard $(10 \%)$.

The musculoskeletal system was the third most common location of neoplasms in our study $(\mathrm{n}=7 / 45$, $15.55 \%)$. In addition to fibrosarcoma $(n=3 / 7,42.85 \%)$ and one hemangiosarcoma (14.28\%), two osteosarcomas were diagnosed $(28.57 \%)$ in one budgerigar and one mallard, together with one osteoma (14.28\%) in a canary. Although osteosarcomas are more frequent than osteomas in pet birds, both neoplasms are uncommon in these birds due to the scarcity of reports $(6,17,51)$, similarly to the low frequency found in the present study.

Although multicentric lymphoma is one of the most commonly diagnosed neoplasms in domestic, freeliving and pet birds such as Psittaciformes and Passeriformes (7, 24, 32, 44, 45, 52), of the neoplasms located in the hemolymphatic system in the present study $(n=5 / 45,11.11 \%)$, only three were multicentric lymphomas $(60 \%)$. One was in a red-lored parrot and in 2 of 5 canaries $(40 \%)$ in which was previously considered common neoplasm (52). In turn, lymphoma in domestic birds have been associated with a herpesvirus (Marek's disease) and a retrovirus (avian leukosis virus); however, there is no evidence that in pet birds this neoplasm is due to a viral infection (52). Lymphoma can have a nodular or diffuse appearance involving a wide range of organs including the liver, spleen, kidneys, integument, bone, gastrointestinal tract, thyroid gland, oviduct, lungs, sinuses, thymus, testes, brain, mesentery, trachea, fat, periorbital muscles and pancreas $(32,52)$. In our study, multicentric lymphomas were found mainly in the gastrointestinal tract (proventriculus, ventriculus, small and/or large intestine). Notably, our case of leukemia, which seems to be rare in pet birds $(5,17)$, was diagnosed in a 20-year-old red-lored parrot showing neoplastic lymphocytes infiltrating the bone marrow, liver and spleen, similarly to those findings diagnosed in an adult double yellow-headed amazon parrot with chronic T-cell lymphocytic leukemia (34). Of the hemolymphatic neoplasms, the mixed thymoma diagnosed in an American robin (Turdus migratorius) was considered to be an uncommon finding, which was in accordance to the current literature $(23,24,44)$. For the diagnosis of this tumor of this bird, in addition to considering to the location (cranioventral of the neck) and histological characteristics of the neoplasm, the immohistochemistry results supported the diagnosis, since lymphoid neoplastic cells showed CD3 intermediate immunopositivity, and the Hassall's corpuscles showed strong immunopositivity for cytokeratin. Thymomas are benign tumors classified as epithelial, lymphocytic or mixed, according to the neoplastic transformation of the cells (24).

Four of the 45 neoplasms $(8.88 \%)$ were located at the digestive system. Squamous cell carcinoma of the tongue was identified in a 1-year-old budgerigar; notably, this neoplasm has been reported with relative frequency in this system $(43,44)$. In addition to the oral cavity, avian squamous cell carcinoma has been identified in the nasal sinuses, esophagus, crop and proventriculus $(28,44)$. The hepatic adenoma found in a budgerigar of our study is considered to be rare in birds. Of the hepatic tumors, cholangiocarcinoma (bile duct carcinoma) appears to be more frequent in avian species affecting several wild, domestic and captive bird species $(11,15,33,44)$. The adenocarcinoma of the cloaca identified in our study in a mallard was also an uncommon finding; however, adenocarcinomas in the digestive tract have been reported relatively frequently in other psittacid birds $(15,25,44)$.

In the respiratory system, only one lung adenocarcinoma was identified in a 28-year-old lilac-crowned amazon $(\mathrm{n}=1 / 45=2.22 \%)$. Few cases of carcinomas or adenocarcinomas located at the nasal or sinus mucosa, glandular epithelium, air sacs or lungs have been previously described in birds $(24,30,40,44,52)$. Tumor metastases to the lungs of pet birds include adenocarcinoma and carcinoma from various primary organs, melanoma, mesothelioma, fibrosarcoma, liposarcoma, lymphoma, and osteosarcoma (52).

In the present study, the use of several primary antibodies (Table 1), which were designed for the diagnosis of neoplasms in humans, indicated a useful 
cross-reaction with bird tissues and represented a valuable diagnostic tool for the identification and classification of neoplasms in this animal species.

The results of our study showed similarities with other retrospective studies conducted in other countries. Regard to a retrospective study in California, USA, the prevalence of neoplasms was also higher in budgerigars (20.6\%) than in other psittacine species (3.6\%), no significant gender-related differences could be demostrated, the skin represented the most often affected organ, and most of the tumors were classified as malignant (13). In another study conducted in Brazil, all birds undergoing surgery belonged to the order Psittaciformes and most neoplasms affected the integumentary system (7), statistics similar to a survey of neoplasia in pet birds conducted in the USA (25). Additionally in another study conducted in the state of Victoria, Australia, budgerigars were the birds mostly affected by neoplasms and fibromas and fibrosarcomas were the second most prevalent tumors (45). Our study provided for the first time knowledge of the neoplastic diseases that occur in ornamental and pet birds in Mexico.

\section{Acknowledgements}

The authors would like to thank the staff of the Hospital de Aves, Departamento de Medicina y Zootecnia de Aves, Facultad de Medicina Veterinaria y Zootecnia, Universidad Nacional Autónoma de México, for support provided to conduct this study.

\section{References}

1. Araújo ACP, Carvalho AD, Nascimento PB, Voll J, Dreimeier D. 2007. Rabdomiossarcoma alveolar em papagaio (Amazona aestiva). Acta Sci Vet. 2007;35:115-7.

2. Bonel J, dos Santos Alberti T, Kramer Fiala Stumm G, de Oliveira Gamba C, Banderra P, Dantas Cassali G. Leiomyosarcoma in a cockatiel. Ciênc Rural. 2019;49(3):e20180858.

3. Bradford C, Wack A, Trembley S, Southard T, Bronson E. Two cases of neoplasia of basal cell origin affecting the axillary region in anseriform species. J avian Med Surg. 2009;23(3):214-21.

4. Bulak K, Łopuszyński W, Lutnicki K, PomorskaZniszczyńska A, Śmiech A, Jodłowska-Jędrych B. Granular cell tumor in a horse: multifocal pulmonary distribution and evidence of autophagy in tumorigenesis. J Equine Vet Sci.2019;79:23-9.

5. Campbell TW. Neoplasia. In: Harrison GJ, Harrison LR, editors. Clinical Avian Medicine and Surgery. Philadelphia: WB. Saunders. 1986. p.500-8.

6. Cardoso JF, Levy MG, Liparisi F, Romão MA. Osteoma in a blue-fronted amazon parrot (Amazona aestiva). J Avian Med Surg. 2013;27(3):218-21.
7. Castro PF, Fantoni DT, Miranda BC, Matera JM. Prevalence of neoplastic diseases in pet birds referred for surgical procedures. Vet Med Int. 2016;4096801.

8. Coleman CW. Lymphoid neoplasia in pet birds: A review. J Avian Med Surg. 1995;9(1):3-7.

9. Dezfoulian O, Abbasi M, Azarabad H, Nouri M, Kiani K. Cerebral neuroblastoma and pituitary adenocarcinoma in two budgerigars (Melopsittacus undulatus). Avian Dis. 2011;55(4):704-8.

10. Doneley B. Avian medicine and surgery in practice: Companion and aviary birds. Appendix 3: Biological values for some common companion bird species. 2nd ed. Boca Raton (FL): CRC Press, Taylor and Francis Group. 2016. 467p.

11. Elangbam CS, Panciera RJ. Cholangiocarcinoma in a blue-fronted amazon parrot (Amazona estiva). Avian Dis. 1988;32(3):594-6.

12. Filgueira KD, Cisneiros da Costa RPF. Carcinoma dérmico de células escamosas em galo (Gallus gallus domesticus) geriátrico. Ciênc An Bras. 2009;19(3):997-1001.

13. Filip T, Scope A. Prevalence of tumors in Budgerigars (Melopsittacus undulatus). Proc Assoc Avian Vet, Monterey, California. 2002. p.189-92.

14. Filippich L. Tumor control in birds. Semin Avian and Exot Pet Med. 2004;13(1):25-43.

15. Gibbons PM, Busch MD, Tell LA, Graham JE, Lowenstine LJ. Internal papillomatosis with intrahepatic cholangiocarcinoma and gastrointestinal adenocarcinoma in a peach-fronted conure (Aratinga aurea). Avian Dis. 2002;46(4):1062-9.

16. Godoy SN, Alves FVA, Kanamura CT, Matushima ER. Neoplasic processes in psittacines birds kept in captivity. Pesq Vet Bras. 2009;29(6):445-51.

17. Javdani M, Hashemnia M, Nikousefat Z, Ghasemi M. Extraskeletal osteoma in a canary (Serinus canaria). Vet Res Forum. 2017;8(3):265-8.

18. Jepson L. Exotic animal medicine: A-quick reference guide. Parrot and related species. London: Sunders Ltd. Elsevier. 2009. 175p.

19. Johne R, Konrath A, Krautwald-Junghanns ME, Kaleta EF, Gerlach H, Muller H. 2002. Herpesviral, but no papovaviral sequences, are detected in cloacal papillomas of parrots. Arch Virol. 2002;147(10):8691880.

20. Jones MP, Orosz SE, Richman LK, Daniel GB, Bochsler PN. Pulmonary carcinoma with metastases in a Moluccan cockatoo (Cacatua moluccensis). J Avian Med Surg. 2001;15(2):107-13.

21. Keller KA, Beaufrère H, Brandão J, McLaughlin L, Bauer R, Tully TN Jr. Long-term management of ovarian neoplasia in two cockatiels (Nymphicus hollandicus). J Avian Med Surg. 2013;27(1):44-52.

22. Langohr IM, Garner MM, Kiupel M. Somatotroph pituitary tumors in budgerigars (Melopsittacus undulatus). Vet Pathol. 2012;49(3):503-7. 
23. Latimer KS, Rakich PM Weiss R. Thymoma in a finch. J Avian Med Surg. 2001;15(1):37-9.

24. Latimer KS. Oncology. In: Ritchie BW, Harrison GJ, Harrison LR, editors. Avian medicine: principles and application. Lake Worth, FL: Wingers Publishing, Inc.; 1994. p.640-72.

25. Leach MW. A survey of neoplasia in pet birds. Semin Avian Exotic Pet Med. 1992;1(2):52-64.

26. Ledesma N, Méndez A, Morales E. Diffuse unilateral seminoma in a fighting rooster (Gallus gallus). Braz $\mathbf{J}$ Vet Pathol. 2018;11(1):32-6.

27. Levine BS. Companion animal practice. Common disorders of amazons, australian parakeets, and african grey parrots. Semin Avian Exotic Pet Med. 2003;12(3):125-30.

28. Lightfoot TL. Clinical avian neoplasia and oncology. In: Harrison GL, Lightfoot TL, editors. Clinical Avian Medicine. Vol. 2. Palm Beach, Florida: Spix Publishing; 2006. p.560-5.

29. Literak I, Smıd B, Valıcek L. Papillomatosis in chaffinches (Fringilla coelebs) in the Czech Republic and Germany. Vet Med-Czech. 2003;48(6):169-73.

30. Loukopoulos P, Okuni JB, Micco T, Garcia JP, Uzal FA, Diab SS. Air sac adenocarcinoma of the sternum in a quaker parrot (Myiopsitta monachus). J Zoo Wildl Med. 2014;45(4):961-5.

31. Malka S, Keirstead ND, Gancz AY, Taylor WM, Smith DA. Ingluvial squamous cell carcinoma in a geriatric cockatiel (Nymphicus hollandicus). J Avian Med Surg. 2005;19(3):234-9.

32. Nemeth NM, Gonzalez-Astudillo V, Oesterle PT, Howerth EW. A 5-year retrospective review of avian diseases diagnosed at the Department of Pathology, University of Georgia. J Comp Path. 2016;155(23):105-20.

33. Nouri M, Marjanmehr SH, Sasani F. Intrahepatic cholangiocarcinoma and encephalomalacia in a budgerigar (Melopsittacus undulatus). Iran $\mathrm{J}$ Vet Med. 2012;6(1):51-5.

34. Osofsky A, Hawkins MG, Foreman O, Kent MS, Vernau W, Lowenstine LJ. T-cell chronic lymphocytic leukemia in a double yellow-headed Amazon parrot (Amazona ochrocephala oratrix). J Avian Med Surg. 2011;25(4):286-94.

35. Ozaki K, Kinoshita H, Kurasho H, Narama I. Cutaneous myelolipoma in a peach-faced lovebird (Agapornis roseicollis). Avian Pathol. 1996;25(1):131-4.

36. Paraschiv I, Militaru M, Tudor L. Epidemiologic study and morphologic diagnosis on lesions identified in psittacines. Scientific Works. C Series. Vet Med. 2012;58(4):286-95.

37. Patnaik AK. Histologic and immunohistochemical studies of granular cell tumors in seven dogs, three cats, one horse, and one bird. Vet Pathol. 1993;30(2):176-85.
38. Prosperi A, Chiari M, Zanoni M, Gallina L, Casà G, Scagliarini A, Lavazza A. Identification and characterization of Fringilla coelebs papillomavirus 1 (FcPV1) in free-living and captive birds in Italy. $\mathrm{J}$ Wildl Dis. 2016;52(3):756-8.

39. Quist CF, Latimer KS, Goldade SL, Rivera A, Dein FJ. Granular cell tumour in an endangered Puerto Rican Amazon parrot (Amazon vittata). Avian Pathol. 1999;28(4):345-8.

40. Raidal SR, Shearer PL, Butler R, Monks D. Airsac cystadenocarcinomas in cockatoos. Aust Vet J. 2007;84(6):213-6.

41. Razmyar J, Dezfoulian O, Peighambari SM. Ossifying fibroma in a canary (serinus canaria). J Avian Med Surg. 2008;22(4):320-2.

42. Reavill DR, Dorrestein GM. Pathology of aging psittacines. Vet Clin North Am Exot Anim Pract. 2010;13(1):135-50.

43. Reavill DR. Pet bird oncology. Proc Assoc Avian Vet, Avian Specialty Advanced Program, Orlando, FL. 2001. p.29-43.

44. Reavill DR. Tumors of pet birds. Vet Clin North Am Exot Anim Pract. 2004;7(3):537-60.

45. Reece R. Observations on naturally occurring neoplasms in birds in the state of Victoria, Australia. Avian Pathol. 1992;21(1):3-32.

46. Rekhi B, Jambhekar NA. Morphologic spectrum, immunohistochemical analysis, and clinical features of a series of granular cell tumors of soft tissues: a study from a tertiary referral center. Ann Diagn Pathol. 2010;14(3):162-7.

47. Saied A, Beaufrère H, Tully TN Jr, Wakamatsu N. Bilateral seminoma with hepatic metastasis in a cockatiel (Nymphicus hollandicus). J Avian Med Surg. 2011;25(2):126-31.

48. Schmidt RE, Quesenberry K. Neoplasia. Neoplastic diseases. In: Altman RB, Clubb SL, Dorrestein GM, Quesenberry K, editors. Avian Medicine and Surgery. Philadelphia: WB Saunders. 1997. p.590-603.

49. Schmidt RE, Reavill DR, Phalen D. Reproductive system. In: Schmidt RE, Reavill DR, Phalen DN, editors. Pathology of pet and aviary birds. 2nd ed. New Jersey: John Wiley \& Sons, Inc. 2015. p.145-60.

50. Schmidt RE, Reavill DR, Phalen DN. Integument. In: Schmidt RE, Reavill DR, Phalen DN, editors. Pathology of pet and aviary birds. 2nd ed. New Jersey: John Wiley \& Sons, Inc. 2015. p.237-62.

51. Schmidt RE, Reavill DR, Phalen DN. Musculoskeletal system. In: Schmidt RE, Reavill DR, Phalen DN, editors. Pathology of pet and aviary birds. 2nd ed. New Jersey: John Wiley \& Sons, Inc. 2015. p.199-220.

52. Schmidt RE, Reavill DR, Phalen DN. Respiratory system. In: Schmidt RE, Reavill DR, Phalen DN, editors. Pathology of pet and aviary birds. 2nd ed. New Jersey: John Wiley \& Sons, Inc. 2015. p.21-53. 
53. Shrader TC, Carpenter JW, Cino-Ozuna AG, Andrews GA. Malignant melanoma of the syrinx and liver in an african grey parrot (Psittacus erithacus erithacus). J Avian Med Surg. 2016;30(2):165-71.

54. Simova-Curd S, Nitzl D, Mayer J, Hatt JM. Clinical approach to renal neoplasia in budgerigars (Melopsittacus undulatus). J Small Anim Pract. 2006;47(9):504-11.

55. Sledge DG, Radi ZA, Miller DL, Lynn BS. Subcutaneous haemangiosarcoma in a cockatiel (Nymphicus hollandicus). J Vet Med A Physiol Pathol Clin Med. 2006;53(6):293-5.

56. Suchy A, Weissenböck H, Schmidt P. Intracranial tumours in budgerigars. Avian Pathol. 1999;28:12530.

57. Tavella VJ, Walters JN, Crofton LM, Leroith T. Mixed germ cell tumor composed of a tridermic testicular teratoma and seminoma in a rooster. J Vet Diagn Invest. 2019;31(3):395-8.

58. Tell LA, Woods L, Mathews KG. Basal cell carcinoma in a blue-fronted Amazon parrot (Amazona aestiva). Avian Dis. 1997;41(3):755-9.

59. Wilson L, Linden PG, Lightfoot TG. Concepts in behavior and development: Section II. Early psittacine behavior and development. In: Harrison GJ and Lightfoot TL editors. Clinical Avian Medicine Vol. 1. Palm Beach (FL): Spix publishing. 2006. p.60-72. 